\title{
An Interactionist Approach to Learning Disabilities
}

\author{
Hilary Scruton ${ }^{1, *} \&$ John McNamara ${ }^{1}$ \\ ${ }^{1}$ Child and Youth Studies, Brock University, St.Catharines, Canada \\ *Correspondence: Child and Youth Studies, Brock University, St.Catharines, ON, L2S 3A1, \\ Canada.E-mail: hs10qw@brocku.ca
}

Received: September 7, 2015 Accepted: October 28, 2015 Published: December 18, 2015

doi:10.5296/ije.v7i4.8260 URL: http://dx.doi.org/10.5296/ije.v7i4.8260

\begin{abstract}
Traditional approaches to understanding learning disabilities date back to the early twentieth century and are based primarily on medical models. Several useful strategies and techniques emerged from these early models and still influence today's classrooms. However, there are also disadvantages to traditional approaches in that the models place much of the burden of the disability on the individual. Post-modern and strength-based perspectives on learning disabilities have attempted to account for the drawbacks of traditional models and have re-framed learning disabilities in broader social and cultural contexts. The current paper reviews these three perspectives and offers an alternative approach that attempts to bridge the modern and post-modern perspectives on learning disabilities. The interactionist approached offered in this paper calls for a processural or multi-faceted conception of learning disabilities. Interactionism encourages educators and students with and without learning disabilities to engage differences in ways that explore possibilities for productive and positive learning from each other.
\end{abstract}

Keywords: Learning disabilities, alternative perspectives, strengths based 


\section{Introduction}

Recently, the field of learning disabilities has experienced a shift. This shift is perhaps best characterized in Malcolm Gladwell's (2013) book," David and Goliath: Underdogs, Misfits, and the Art of Battling Giants". In his chapter on Dyslexia, Gladwell presents examples of individuals with learning disabilities who have succeeded because of their disability. The purpose of the chapter is to focus on strengths - strengths that have arisen because of the existence of the individual's learning disability, not in spite of it. Following this, several books, movies, and popular media outlets have re-focused our attention on the strengths that arise from having a learning disability. In fact, the concept of adversity in general may be experiencing such a shift in paradigms. The notion of re-framing adversity has become a significant focus in the field. And indeed, this is a worthwhile pursuit. However, this shift invites the question of whether this paradigmatic pendulum swing has been too severe. Traditional approaches to learning disabilities have dominated our clinical, academic, and research forums for decades. At this point, during our shift towards post-modern and strength-based models, it is important to reflect on the utility of both traditional and new approaches to learning disability. This article will explore these perspectives and present a possible solution to balancing these approaches.

\section{Traditional Approaches to Learning Disabilities}

Over the past several decades the field of learning disabilities has evolved through many causal or explanatory frameworks. All of these frameworks have been steeped in a medical model whereby the "disability" has resided within the individual and the role of institutions (i.e. schools, programs, LDAs, etc.) has been to reverse the trajectory of the "disabled child".

\subsection{The Medical Model}

The earliest model of learning disabilities emerged directly from the field of medicine. In the 1940s and 50s the field of medicine began to distinguish between individuals with exogenous and endogenous mental retardation (Strauss \& Lehtinen, 1947). Researchers began to hypothesize that there were some individuals classified as mentally retarded who were, in fact, not mentally retarded. Instead, these individuals were thought of as having minimal brain damage that affected their intellectual functioning. The etiology of the decreased intellectual functioning was assumed to reside in the individual's biological or neurological system, namely the central nervous system. Research in this area was characterized by nomothetic approaches that emphasized the intrinsic neurological damage within the individual (Strauss \& Lehtinen, 1947). Furthermore, individuals who suffered from this type of disability were thought to be part of a homogeneic population. Hence, research would compare narrow samplings of human performance that were thought to be related to the decreased intellectual functioning of the population (Rourke \& Del Dotto, 1994). The subsequent educational prescriptions were based on the results of this research and attempted to remediate the neurological damage.

The medical model of learning disabilities may have been an attractive avenue for researchers 
to pursue specifically because it assumes the objective reality of observed symptoms and also assumes that the disability has been caused by factors that can be objectively identified and treated. Assuming this, the study of the underlying causes could be uncovered with empirical methods and subsequent treatment could be prescribed to the entire population. However, for the most part, the medical model of learning disabilities has been unsuccessful in isolating the neurological or biological variables that may cause learning disabilities (Kavale \& Forness, 1995).

\subsection{The Psycholinguistic Model}

During the 1960s the field turned away from the neurological basis for learning disabilities and began to examine the linguistic processing difficulties that individuals with learning disabilities encountered. One of the prominent researchers in this area was Samuel Kirk. Kirk led the movement to move away from the term, "minimally brain damaged", to "psycholinguistically handicapped", and eventually to "learning disabled" (Kirk \& Bateman, 1962). This psycholinguistic model emphasized the linguistic or phonological processing difficulties experienced by individuals with learning disabilities.

However, like the medical model of learning disabilities, psycholinguistic diagnostic testing often failed to find unequivocal differences between the processing of students with and without learning disabilities. The testing done using this model often lacked reliability and results of research often could not be replicated. Furthermore, educators began to realize that it was not enough to focus exclusively on direct phonological processing training. Such intervention was not effective in increasing the academic performance of students with learning disabilities. Students undergoing phonological processing training could not be successfully integrated into the regular classroom. This narrow model did not adequately account for the academic and social abilities and development of students with learning disabilities.

\subsection{The Cognitive Model}

The 1970/80s saw the field of learning disabilities move towards a cognitive model. This model emphasized theories of information processing and cognitive strategy training. Individuals with learning disabilities were thought to have a deficit in their ability to process cognitive or psychological information. This was thought to be caused by a malfunction in the area of the central nervous system that coordinated activities such as language, memory, attention, and perception (De Ruiter, Ferrell \& Kass, 1975). Diagnosis of learning disabilities using this model focused on the discrepancy between achievement and potential that was revealed by cognitive skill testing designed to measure the individual's ability to utilize cognitive linguistic strategies. Cognitive researchers believed that students with learning disabilities may have performance rather than ability difficulties. In other words, these students could not process and utilize appropriate cognitive strategies to successfully complete tasks. Cognitively based educational treatments involved the teaching of cognitive and metacognitive strategies that would enable students to successfully perform academic tasks. Cognitive educational interventions were concerned with how the child learns rather than what the child learns. 
One of the difficulties with the traditional cognitive research is the examination and manipulation of hypothetical constructs such as memory and perception. Often, students' memory or perceptual constructs are isolated and measured within a laboratory setting and the subsequent results are generalized to the population and real school and life settings in question. However, the measurement of hypothetical constructs often led to inconsistent results. Cognitive models of learning disabilities, and more recently metacognitive models of learning disabilities, have played an integral role in the development of the field of learning disabilities.

\section{Recognizing the Problem}

In general our traditional discourses of learning disability have centered around identifying children with learning disabilities as those who fall below the a particular percentile (17th or 25 th, etc.) on various measures of achievement. Following this, children identified with learning disabilities are deemed as requiring "special" services such as IEPs, resource room instruction, therapeutic services, etc. Such programs and services are often very useful in supporting children with their reading achievement, or math skills, etc., to achieve within "normal" limits. However, it is important also to recognize that children with learning disabilities, along with their families, are inundated with one salient message - your child has "special needs". It is not a surprise therefore, that many children with learning disabilities often struggle with co-morbid disabilities such as mental health issues including depression, anxiety, and so forth. These struggles may arise from a phenomenon deemed "the Matthew effect" or "the rich get richer and the poor get poorer" (McNamara, Scissons \& Gutknecht, 2011; Stanovich, 1986). This effect posits that as grades progress, children with special needs fall increasingly behind their grade level peers in their reading, or math, etc. One interesting aspect about the Matthew effect is that children with learning disabilities are not falling further behind their peers because of their academic skills deficits per se. Rather, they are falling further behind because of an increasing lack of motivation to engage. In this sense, the Matthew effect may be caused in part, by children comparing themselves to their peers. Such comparisons can lead to low self-esteem, self-worth, and potentially mental health related issues. There are several examples of such a cycle that have been recently publicized in popular media (e.g. Raymond, 2011). It is no surprise therefore, that authors such as Gladwell and others have attempted to disrupt the traditional discourses around the term "disability" to engage an alternative discourse - to present an alternative for children with disabilities.

\section{Alternative Approaches}

The recent focus on re-framing adversity and learning disabilities may have roots in post-modern theoretical perspectives. Post-modern theorists have attempted to address the shortcomings of the traditional scientific approaches to learning disabilities. Post-modern approaches to disability are not a novel idea. In his first book, History of Madness, Foucault (1961) writes about the seventeenth century social hegemony punishing, controlling, and 
ultimately curing those deemed "mad" in order to protect society from undesirables and to regulate unemployment and wages. This notion of controlling individuals who did not "fit within the limits" of what was considered normal, is an early rendering of post-modern thought on disability. In a later work around Foucault's perspectives on power and disability, Tremain (2005) uses Foucault's critical disability theory to reframe many factors surrounding disabilities in our current educational and political systems. Foucault's general thought around disability is that the concept is socially constructed by power brokers in order to maintain a certain social order. For instance, learning disabilities are socially constructed as something that resides within an individual such that it is the individual who needs to be remediated. This is a useful position for school boards in that they can continue to teach to the "middle of the curve" without considering children who fall as outliers. Foucault may argue that learning disabilities was a social or educational manipulation whereby schools were using the term "learning disabilities" to account for children outside of the normal curve that the system could not effectively reach. Proponents of this approach would argue that learning disabilities was simply a "sociological sponge" used to mop up the mess left behind by the general education curriculum (Lyon, et al., 2001). Educational institutions do not want to be concerned with anything but pushing forward an agenda of teaching children to develop into average, productive citizens (Tremain, 2005).

Similar to Foucault, Deluze and Guattari (1987) explore ways to disrupt traditional discourses around power and institutions to offer a useful post-modern perspective on disability. Deluze and Guattari may be somewhat more pragmatic than Foucault in that they push society to re-imagine disability as something that enables possibilities that would not be present otherwise. Deleuze and Guattari (1987) introduce the concept of the rhizome as a metaphor for understanding politics, social life, literature, history, sexuality and disability. The notion of a rhizome is used as an analogy for a possible system that values heterogeneity. By re-imagining an educational system as non-linear and multi-faceted, the diverse nature of children living and working within the system is recognized and valued. This is a useful position to begin discourse about general education curriculum that reaches all learners, including those with learning disabilities.

Allan (2011) attempts to engage new conversations about disability. Using the sociocultural frameworks of Deleuze and Guattari, Derrida, and Foucault, Allan critiques and deconstructs traditional notions of disability locating the point of "Otherness" in our social system and calling for an opening up of discourse about the "Other". Allen (2011) describes the difficulties associated with the notion of logocentrism, or the philosophical notion of external truth or structure - a concept akin to the medical model of learning disability described early in this paper. Allen explains how logocentric structures of normalcy have led to the concept of the Other, or what Derrida (2002) explains as the notion of something that is outside of the Same or outside of what is considered as normal. Allen (2011) invites educators and researchers in the field of disability to adopt a philosophy of difference where dialogue about the Other is valued and worthwhile. Allen (2011) also calls for stakeholders to incorporate discourse around the Other in their methodologies, practices, and classrooms. Although recognized as difficult, practices of difference may include resisting demands for success 
criteria in academic tasks and perhaps offering frameworks for failing effectively - concepts not commonly adopted in our classrooms.

Hughes (2005) offers a critique of Foucault's post-modern notion of disability in an attempt to empower individuals with disabilities. Hughes (2005) recognizes the social constructivist underpinnings of disability but critiques Foucault and other's perspectives on power and disability as these theorists view individuals with disabilities as passive targets of power structures. That is, Foucault does not sufficiently recognize individuals with disabilities as agentic beings who can transcend their dependency as subjects (Hughes, 2005). Hughes argues that a more useful perspective would be to see individuals with disabilities as holding the possibility to embody their own experiences rising to overcome discrimination and succeed within a traditional society. Hughes' perspective is a productive lead into notion of the "underdog" as proposed by Gladwell (2013).

In his book, "David and Goliath: Underdogs, Misfits, and the Art of Battling Giants", Gladwell (2013) explains how vulnerable populations can engage with adversity while living within traditional environments. Gladwell presents an alternative perspective for thinking about individuals and groups who fall outside of our "normal curve". The essence of his argument is that individuals' challenged by adversity engage their own selves in unique ways - ways that "typically achieving" individuals do not. For instance, in his chapter, "You wouldn't wish dyslexia on your child. Or would you?" Gladwell describes how many individuals with dyslexia attribute their success in life to actually having dyslexia. In multiple case studies, Gladwell uncovers how many successful entrepreneurs, innovators, and business people with dyslexia grew up in traditional reading-based environments without the ability to read effectively. In order to simply survive within their academic situations, these individuals relied on other skills (i.e. their ability to negotiate, or listen, or observe). In fact, they practiced these other skills an inordinate number of times compared to their typically achieving peers. By the simple law of "the practice effect", these individuals became skilled negotiators, listeners and observers - skills that would serve them well in their careers. In this way, these individuals succeeded not in spite of their dyslexia, but because of it.

Eide and Eide (2011) take a similar viewpoint in their book, "The Dyslexic Advantage: Unlocking the Hidden Potential of the Dyslexic Brain". The authors present an interesting notion that that there are distinct advantages to having dyslexia. Like Gladwell (2013), Eide and Eide (2011) site numerous examples of individuals with dyslexia who have reached tremendous levels of success. It is interesting to note, that almost all of their cited examples have succeeded in fields that also rely on innovation, creativity, and "outside of the box" thinking. The success of these individuals is thought to be associated with the notion that they are using a type of neurological processing that is not otherwise used in academic tasks. Individuals with dyslexia, a presumed left-side neurological processing problem, process information with the right side of the brain - even with tasks that should be processed with the left side (i.e. language). In over-using their right hemisphere it is hypothesized that individuals with dyslexia have well-developed right hemispheres and as such, have strengths associated with this type of processing such as innovation and creativity. In this way, both Eide and Eide (2011) and Gladwell (2013) posit that individuals with dyslexia are succeeding 
in specific ventures because of their dyslexic advantage. Their key message is that brain processing associated with dyslexia is not simply a barrier to learning; rather it is a reflection of an entirely, different pattern of brain organization and information processing-one that predisposes a person to important abilities.

One of the potential challenges with this strengths-based approach is that it neglects to meet the clinical needs of the child with learning disabilities. That is, within today's classrooms, children require literacy and reading to successfully complete school curriculums. Post-modern and more recently, strength-based models of learning disabilities, although useful in promoting a sense of self-worth in areas that de-emphasize reading (i.e. creativity), do not address the educational needs expressed by educators, parents, and even children themselves. As such, it may be important to consider a model that bridges the modern approaches to learning disabilities (i.e. cognitive), the post-modern approaches to disability (i.e. deconstructivist), and strength-based perspectives to adversity (i.e. the underdog). One such approach may be an interactionist perspective on learning disabilities.

\section{An Interactionist Approach}

An interactionist perspective on learning disabilities attempts to bridge the modern and post-modern (Fay, 2014; Martin \& Sugarman, 1996, 1998). As this paper has illustrated, one single underlying framework or model cannot adequately explain learning disabilities. A unitary framework can be successful in explaining one particular component of learning disabilities but does not consider learning disabilities as a whole. Traditional or modernistic approaches tend to place the burden of the disability itself on the individual, thus placing the onus of remediation towards normalcy on the individual. Such approaches only work towards reinforcing traditional frameworks of disability. On the other hand, post-modern approaches, attempt to deconstruct traditional discourses in order to break notions of normalcy. However, postmodern approaches to disability often fall short of providing pragmatic alternatives for practice (see Hughes, 2005). The most recent conceptualizations of learning disabilities (Gladwell, 2013; Eide \& Eide, 2011) have focused on realizing the strengths of individuals and more so, promote developmental trajectories that capitalize on these strengths. However, this approach may not adequately attend to the immediate demands of their educational curriculum.

The interactionist approach attempts to bridge all three perspectives by viewing individuals as both agentic and constrained (Fay, 2014). Furthermore, some individuals are more agentic or more constrained than others. This is important to understand, particularly in the case of individuals with learning disabilities. An interactionist framework is fluid and considers individuals as dynamically evolving and always becoming. A psychological individual is constantly in flux, and changes depending on the sorts of self-referring practices available for appropriation in their sociocultural contexts (Fay, 2014). In this light, an individual identity and sense of self are social and processural in nature, not just self-directed inner processes. Assuming this view of the individual, is not easy to distinguish the self from others. In fact, the very existence of the self is somewhat dependent on the existence of others (Fay, 2014; 
Martin \& Sugarman, 1996, 1998). Interactionism envisions a dynamic social and psychological blending in which the self and others constantly and collectively change. In this respect, the differences between individuals and groups are recognized, scrutonized, situated, challenged, and perhaps transformed.

Researchers and educators often assume a static, binary, and oppositional relationship between individuals with and without learning disabilities. Interactionism would call for a processural or multi-faceted conception of learning disabilities. On the one hand, decades of research have recognized that individuals with learning disabilities have distinct processing problems that require specific remediation. Torgesen (2000) acknowledges that remedial instruction needs to be intensive, explicit, and long lasting. Students with learning disabilities need to work within an appropriately adapted curriculum environment. Curriculum must be structured in such a way to ensure that individuals with learning disabilities can effectively achieve and more so thrive. However, this type of instruction is not enough.

Interactionism encourages educators and students with and without learning disabilities to engage differences in ways that explore possibilities for productive and positive learning from each other. In other words, rather than differentiating instruction for separate groups of students based on ability, interactionism focuses on collaborations among groups regardless of ability. One way of achieving this within a school culture is to encourage all members of a school to appreciate the ways in which every student, including those with learning disabilities, contribute to the self-knowledge of every other student and to the identity of the school as a whole. In other words, students and educators should explore, question, and learn from the differences within the school culture. In this way, students begin to recognize their own distinctiveness from, as well as their relatedness to, other students within the school. Such an environment will foster the notion that the school culture is a dynamic environment that cannot exist without the mutual communion of all its participants (Fay, 2014).

\section{Conclusion}

For years, the field of special education has adopted a binary, categorical model where children with special needs are identified as a distinct population. The purpose of this paper is not to negate the traditional approaches to supporting children with learning disabilities as children live within "traditional" neighbourhoods and learn within "traditional" schools. To meet the demands of their traditional schools, children with learning disabilities often attend intervention programs that look to improve their reading skills in order to be more commensurate with their grade-level peers. Post-modern discourses, on the other hand, attempt to deconstruct disability in order to disrupt the traditional notions of normalcy. This approach is useful in that allows an understanding of the social power structures that may influence how learning disabilities are represented in schools. However, post-modern approaches often fall short of providing pragmatic solutions in line with their deconstructionist positions. The third perspective reviewed in this paper re-frames learning disabilities to focus on their strengths, often right hemispheric processing-based skills such as creativity, innovation, and problem solving. The challenge with this perspective is that it does 
not adequately address traditional educational needs. An interactionist approach finds the utility of all three approaches - recognizing learning disabilities and adversity in a more general sense as natural, resistant, and useful. This alternative discourse emphasizes the need to change our paradigm from one of working towards "normal-ness" to one of recognizing possibility. The proposed "balance of perspectives" may allow children to work towards a goal of improving their academic skills and at the same time releasing their power to think differently about their own adversity thus enlightening them to engage their rare and important contribution to society.

\section{References}

Allan, J. (2011). Complicating and Explicating: Taking up Reason in Learning Disabilities Research. Learning Disability Quarterly, 34(2), 152-161. http://dx.doi.org/10.1177/073194871103400206

Delueze, G., \& Guattari, F. (1987). Introduction: Rhizome (pp. 6-12) in A Thousand Plateaus: Capitalism and Schizophrenia. Minneapolis, MN: University of Minnesota Press. http://dx.doi.org/10.1177/002221947500800608

Derrida, J. (2002). Force of law: the 'mystical foundation of authority'. In G Anidjar (ed.), Acts of Religion.

DeRuiter, J. A., Ferrell, W. R., \& Kass, C. E. (1975). Learning disability classification by Bayesian aggregation of test results. Journal of Learning Disabilities, 8(6), 365-372.

Eide, B., \& Eide, F. (2011). The Dyslexic Advantage: Unlocking the Hidden Potential of the Dyslexic Brain. New York: Penguin.

Fay, B. (2014). Contemporary Philosophy of Social Science. Malden, MS: Blackwell Publishing.

Gladwell, M. (2013). David and Goliath: Underdogs, Misfits, and the Art of Battling Giants. New York: Little, Brown, and Company.

Raymond, A. (Director). (2011). Journey into Dyslexia [Motion picture on DVD]. Video Vérité.

Hempel, C. (1966). Fundamentals of Concept Formation in Empirical Science. Chicago, IL: University of Chicago Press.

Kavale, K. A., \& Forness, S. R. (1995). The Nature of Learning Disabilities: Critical Elements of Diagnosis and Classification. Mahwah, NJ: Lawrence Erlbaum Associates.

Kirk, S. A., \& Bateman, B. (1962). Diagnosis and remediation of learning disabilities. Exceptional Children, 29(2), 73-78.

Kirk, S., McCarthy, L., \& Kirk, S. (1968). Illinois Test of Psychololinguistic Abilities. Urbana, IL: University of Illinois Press. 


\section{Macrothink}

International Journal of Education

ISSN 1948-5476

2015, Vol. 7, No. 4

Lyon, G. R., Fletcher, J. M., Shaywitz, S. E., Shaywitz, B. A., Torgesen, J. K., Wood, F. B., ... \& Olson, R. (2001). Rethinking learning disabilities. Rethinking special education for a new century, 259-287.

Martin, J., \& Sugarman, J. (1998). Dynamic interactionism: Elaborating a psychology of human possibility and constraint. Journal of Mind and Behavior, 19(2), 195-214.

Martin, J., \& Sugarman, J. (1996). Bridging social constructionism and cognitive constructivism: A psychology of human possibility and constraint. Journal of Mind and Behavior, 17(4), 291-319.

McNamara, J. K., Scissons, M., \& Gutknecth, N. (2011). A longitudinal study of kindergarten children at risk for reading disabilities: The poor really are getting poorer. Journal of Learning Disabilities, 44(5), 421-430. http://dx.doi.org/10.1177/0022219411410040

Rourke, B., \& Del Dotto, J. (1994). Learning Disabilities: A Neurological Perspective. Thousand Oaks, CA: Sage Publishing.

Stanovich, K.E. (1986). Matthew effects in reading: Some consequences of individual differences in the acquisition of literacy. Reading Research Quarterly, 21(4), 360-407. http://dx.doi.org/10.1598/RRQ.21.4.1

Strauss, A. A., \& Lehtinen, L. E. (1947). Psychopathology and education of the brain-injured child. American Journal of Psychiatry, 106(10), 796-797.

Tremain, S. (2005). Foucault and the Government of Disability, Ann Arbour, MI, University of Michigan Press.

\section{Copyright Disclaimer}

Copyright for this article is retained by the author(s), with first publication rights granted to the journal.

This is an open-access article distributed under the terms and conditions of the Creative Commons Attribution license (http://creativecommons.org/licenses/by/3.0/). 